\title{
Herbal Medicine for the Treatmentof Viral Infections: A Systemic Review
}

\author{
Amand Alekhya, Abbaraju Krishna Sailaja \\ Department of pharmaceutics, RBVRR women's college of pharmacy, Affiliated to Osmania University, Hyderabad, India.
}

*Corresponding Author: Abbaraju Krishna Sailaja, Department of pharmaceutics, RBVRR women's college of pharmacy, affiliated to Osmania University, Hyderabad, India.

Received date: October 21, 2021; Accepted date: December 27, 2021; Published date: January 07, 2022

Citation: A Alekhya, Abbaraju K Sailaja. (2022). Herbal Medicine for the Treatmentof Viral Infections: A Systemic Review. Biomedical Research and Clinical Reviews. 6(1); DOI: 10.31579/2692-9406/088

Copyright: () 2022 Abbaraju Krishna Sailaja, This is an open access article distributed under the Creative Commons Attributiosn License, which permits unrestricted use, distribution, and reproduction in any medium, provided the original work is properly cited.

\begin{abstract}
The term "Antiviral agents" has been defined in very wide terms as substances other than a virus or virus containing vaccine or specific antibody which can build either a protective or therapeutic effect to the direct measurable advantage of the virus infected host. Viruses are simple in form which are very tiny germs. They comprise of genetic material inside of a protein coating. Viruses cause amicable infectious diseases like common cold, flu and warts. They also cause severe diseases such as HIV/AIDS, Ebola, avian influenzas, dengue virus and COVID-19. Viral diseases are very complex and are easily spread. Herbs and herbal medicines were the foremost in treating infections from centuries over the world in every civilization. Modern science has narrowed the importance of herbal medicine in the past two centuries. But, the side effects and new varieties of diseases creating challenges to modern science. So, usage of herbal medicines is again attaining interests these days. Herbal products for different treatments have achieved a lot of popularity in the last couple of decades. Thus, discovering novel antiviral drugs is of extremely important and natural products are an excellent source for such discoveries. There are many herbs which are excellent sources for the antiviral properties to treat viral infections. This review provides the verified data on the herbal substances with antiviral activity, and some of the herbal marketed antiviral agents like CORONIL TABLETS from Patanjali and different companies had made an attempt to treat viral infections in this pandemic situation. Therefore, herbal plants proved to be a major resort for the treatment of diseases and sickness by traditional healers in many societies.
\end{abstract}

Keywords: different antiviral herbs; viral diseases; marketed herbal products for viral infections

\section{Introduction}

A virus is a tiny contagious agent that replicates inside the cells of living host. When infected, the host cell is enforced to rapidlygive rise to thousands of identical copies of the original virus. Unlike most living things, viruses do not have cells that divide; new viruses gather in the infected host cells. Viruses are made up of two or three parts which includes genes, these genes are composed of encoded biological information of the virus and are fabricated from either DNA or RNA. Genes present in the viruses are shielded with a protein coat [1].

A viral infection is a proliferation of a harmful virus inside the body which infect the host by launching their genetic material into the cells and hijacking the cells internal machinery to make more virus particles. Viral diseases are exceedingly widespread infections caused by viruses. They cause many transmissible diseases like common cold, influenza, yellow fever, rabbis, measles, many forms of diarrhea, hepatitis, polio. Even currently many viral infections are still causing huge threat to human being such as coronavirus, HIV, SARS, Ebola virus, Dengue virus, etc. where there are no efficient conventional medications or vaccines for most of these viruses. There are different kinds of viral infections which are as follows.

\section{Types of viral infections:}

There are many viral infections which effect the human body at different sites [2].

\section{1) Respiratory viral diseases:}

Respiratory viral infections are transmissible and commonly affect the upper or lower parts of respiratory tracts.Based on symptoms and local epidemiology viral infections are clinically determined. This is severely affected in older patients and infants. Common symptoms of respiratory viral infections include: body aches, fever, coughing or sneezing, runny or stuffy nose [3].

Examples: Coronavirus, severe acute respiratory syndrome (SARS), flu, common cold, parainfluenza virus infection, adenovirus infection, respiratory syncytial virus infection. 
- $\quad$ Respiratory viral infections usually heal on their own, but over the counter (OTC) medications, such as cough suppressants, nasal decongestants and pain relievers can help to lower the symptoms.

- $\quad$ The best way to avoid respiratory viral infections is to practice good personal hygiene, wash your hands often, cover your mouth when you cough or sneeze and limit your interactions with the people who show symptoms.

\section{$\bullet$}

\section{2) Gastrointestinal viral diseases:}

Gastrointestinal viral infections, in which the virus affects the digestive tract which usually lead to a condition called gastroenteritis, commonly called as stomach flu. Common symptoms of gastrointestinal viral infections include: vomiting, diarrhea, abdominal cramps [4].

Examples: norovirus infection, rotavirus infection, astrovirus infection.

\section{3) Exanthematous viral diseases:}

In this the viruses causes skin rashes and many more symptoms; these infections are highly contagious [5, 6].

Examples: Measles, rubella, chickenpox, smallpox, chikungunya virus infection.

- $\quad$ Many exanthematous virus spread through respiratory droplets from the cough or sneeze of someone with virus.

- Measles, rubella, chickenpox and smallpox these all can be prevented by vaccination.

\section{4) Hepatic viral diseases:}

The hepatic viral diseases which cause inflammation of the liver known as viral hepatitis. Sometimes it may be caused by other viruses such as cytomegalovirus and the yellow fever virus [7].

Examples: Hepatitis type A, B, C, D \& E.

- $\quad$ Hepatitis A \&E can be transmitted by food and water that's been contaminated with the virus, whereas Hepatitis B \&C can be transmitted from person to person by bodily fluids and hepatitis B can be spread through sexual contact.
- $\quad$ There are vaccines for both Hepatitis A \& E, and by taking antiviral drugs which are prescribed by the physician.

\section{5) Cutaneous viral diseases:}

Cutaneous viral infections cause lesions or papules are formed on the skin. In many cases, these lesions can stick around for a long period of time or come back after disappearing for a while [8].

Examples: warts (including genital herpes), oral herbs, genital herbs, molluscum contagiosum.

- $\quad$ These viruses are transmissible which are usually outspread through close physical contact with someone who has the virus.

- $\quad$ It can be prevented by maintaining good hygiene habits.

\section{6) Hemorrhagic viral diseases:}

Hemorrhagic viral infections are dreadful conditions that involves damage to your circulatory system. Symptoms by these infections include high fever, body aches, bleeding in internal organs, weakness, bleeding under the skin, bleeding from the mouth or ear [9].

Examples: Ebola, Lassa fever, dengue fever, yellow fever, Marburg hemorrhagic fever.

- $\quad$ There's no specific treatment for hemorrhagic viral diseases, researchers are in process of developing vaccines for several hemorrhagic viruses.

- A yellow fever vaccine is available for people who are travelling to the areas where the yellow fever is common.

\section{7) Neurologic viral diseases:}

Some viruses even they can affect brain and surrounding tissues, causing neurologic viral diseases. This can result in the range of symptoms like fever, confusion, drowsiness, seizures, coordination problems [10].

Examples: polio, viral meningitis, viral encephalitis, rabies.

- $\quad$ Polio virus and mumps virus, which can cause meningitis and encephalitis can be prevented by taking vaccine.

- Rabies can be prevented from spreading by properly vaccinating our pets and avoid approaching wild animals. 


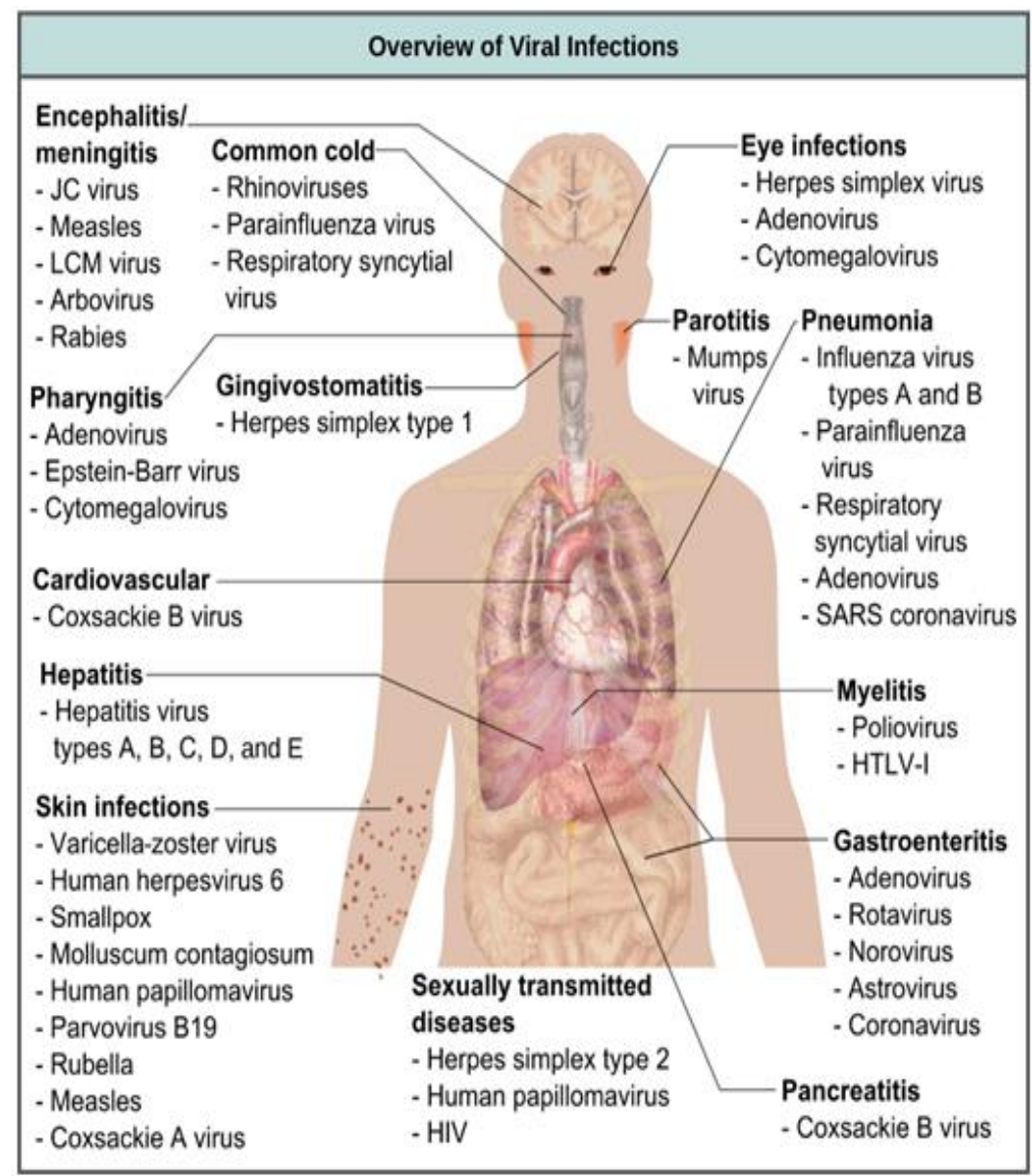

Figure 1: Overview of different viral infections in the human body

\section{Antivirals: an herbal approach}

\section{Herbal antiviral medicine: an introduction}

The term "Antiviral agents" has been defined in very wide terms as substances other than a virus or virus containing vaccine or specific antibody which can build either a protective or therapeutic effect to the direct measurable advantage of the virus infected host. All over the world, herbal medicines are reviewed to be one of the most significant areas of interest in traditional medicine systems. Classic antiviral drugs are often costly and ineffective due to viral resistance and cause severe adverse effects, with that in mind naturally based herbal medicines will be a proper alternative for treating viral diseases. World Health Organization (WHO) has also highlighted in 1978, on the importance of scientific research into herbal medicine and all the developing countries has started research on their native medicinal plants and to get register to the WHOs list of "essential drugs" [11].

WHO has published a report in which it is mentioned that nearly $80 \%$ of people living in rural areas depends on medicinal plants as primary health care system and their practices entirely based on knowledge of traditional use of medicinal plants? According to a FAO report, at least $25 \%$ of drugs used in modern pharmacopoeia are acquired from plant products. Some of the herbs or medicinal plants having antiviral properties against different viruses and these are used since ancient times because of their stronger therapeutic effect.

Herbal medicines and purified natural products furnish a rich resource for novel antiviral drug development. Recognition of the antiviral mechanisms from these herbal agents has shed light where these agents interact with the viral life cycle, such as viral entry, replication, assembly and release, furthermore on the targeting of virus host specific interactions.

\section{Herbs with antiviral activity:}

Since ancient times, many herbs have been used as natural treatments for various illnesses, including viral infections. Due to the presence of phytochemicals and potent plant compounds, many herbs help fight against viruses. Common kitchen herbs like basil, sage and oregano, as well as lesser-known herbs like Astragalus and Sambucus have powerful antiviral effects against numerous viruses that cause infections in humans. Many researchers have conducted research of herbs but they could not mention whether the small dose or high dose of the concentrated extract would have the same effects on humans. There are many herbs like basil, sage, ginger, ginseng, etc.; which have antiviral properties, some of them are mentioned below.

1) Ginger: It has impressive antiviral, antibacterial and antiinflammatory properties. Ginger contains compound such as gingerols and zingerone that helps to prevent the growth of the virus and this herb is effective in avian influenza, RSV and feline calicivirus (FCV). Fresh ginger of uplifted concentration could stimulate mucosal cells to release IFN- $\beta$ that possibly contributed to counteracting viral infections $[12,13]$.

2) Sage: This is an aromatic traditional herb of the mint family has long been used for the treatment of viral infections. The leaves and stem of this herb contain a compound called safficinolide, which shows antiviral properties. It is also used for treating different kinds of disorders icluding saizures, ulcers, gout, rheumatism, inflammation, dizziness, tremor, paralysis, dairrhea and hyperglycemia [14]. 
3) Basil: It has both antiviral and anti-inflammatory properties that can help fight several viral infections. Basil leaves contains active constituents like apigenin and ursolic acid, which is helpful in treating virus like herpes, hepatitis B and enterovirus. The crude aqueous and ethanolic extracts of basil and selected purified components like apigenin, linalool and ursolic acid, exhibited a broad spectrum of antiviral activity [15].

4) Oregano: It is an herb from mint family with powerful antiviral properties. The plant contains active phytochemical like carvacrol that alone exhibited high antiviral activity against rotavirus and even it has antibacterial and antifungal properties [16].

5) Garlic: It is a superfood which is used for preparing medicines for various health conditions, it can be effective against influenza $A$ and B, HIV, HSV-1, viral pneumonia and rhinovirus [17].

6) Ashwagandha: It is scientifically known as "WITHANIA SOMNIFERA" (WS) is an important medicinal plant that has been used in ayurvedic and indigenous medicine for more than 3000 years.It is composed of an active chemical constituent called withaferin $\mathrm{A}$, has been shown to have a broad range of medicinal properties including antiviral activity. The hydro alcoholic extract of withania somnifera roots showed the inhibition of virus at maximum
$99.9 \%$ in its highest nontoxic concentration. It is mainly used for the treatment of influenza virus [18, 19].

This ancient medicinal herb provides almost every health benefit like from improving immunity to reducing stress, regulating blood sugar level and lowering cholesterol. A recent research showed that ashwagandha contains certain bio-actives that interacts with SARSCO-2. This herb contains a natural compound called withanone (Wi$\mathrm{N}$ ), that can block the replication process of the novel virus and treat the condition [20].

7) Giloy: It is scientifically called as "Tinospora cordifolia" and is commonly named as "Guduchi" in Sanskrit which has excellent applications in treating various diseases. This plant has many benefits and it is powerhouse of anti-oxidants which helps to neutralize free radicals and prevents from inflammation. It has other benefits like it purifies blood, boosts immunity, flushes out toxins from the body and fights against bacteria and viruses.Consuming giloy juice can help you get rid of fever, which is one of the signs of COVID-19 pandemic situation. Because of its anti-inflammatory properties it helps in dealing with the respiratory problems like cough, cold and breathing problems which are major signs of novel coronavirus infection $[21,22]$. Marketed herbal medicines are given in figure2.

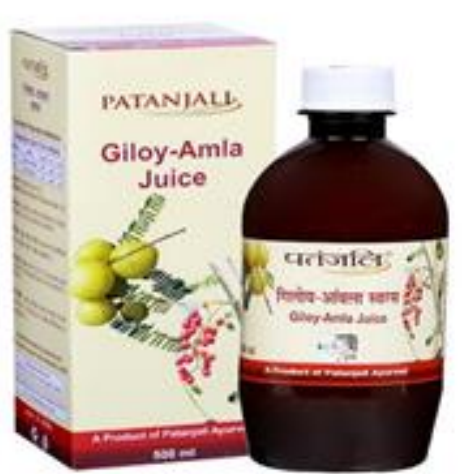

Figure 2: Herbal marketed medicines of Giloy ghanvati tablets and giloy-amla juice by PATANJALI pvt Ltd.

\begin{tabular}{|c|c|}
\hline Virus name & Plant with antiviral properties \\
\hline Herpes simplex virus & $\begin{array}{c}\text { Allium sativum (Liliaceae) } \\
\text { Mangifera indica (Anacardiaceae) } \\
\text { Solanum nigrum (Solanaceae) }\end{array}$ \\
\hline Adenovirus & $\begin{array}{c}\text { Camellia sinensis (Theaceae) } \\
\text { Ocimum basilicum (Lamiaceae) }\end{array}$ \\
\hline Influenza virus & $\begin{array}{c}\text { Echinacea (Asteraceae) } \\
\text { Allium oreoprasum (Alliaceae) } \\
\text { Asparagus filicinus (Asparagaceae) } \\
\end{array}$ \\
\hline Hepatitis B virus & $\begin{array}{c}\text { Polygonum cuspidatum (polygonaceae) } \\
\text { Boehmeria nivea (Urticaceae) }\end{array}$ \\
\hline Hepatitis $\mathrm{C}$ virus & Saxifrage melonocentra (Saxifragaceae) \\
\hline Polio virus & Piper aduncum (Piperaceae) \\
\hline Coronavirus & Echinacea (Asteraceae) \\
\hline Rhinovirus & Echinacea (Asteraceae) \\
\hline $\begin{array}{c}\text { Severe acute respiratory syndrome-associated } \\
\text { coronavirus }\end{array}$ & Lycoris radiate (Amaryllidaceae) \\
\hline Coxsackie viruses & Echinacea (Asteraceae) \\
\hline Dengue virus & $\begin{array}{c}\text { Azadirachta indica (Meliaceae) } \\
\text { Kaempferia parviflora (Zingiberaceae) }\end{array}$ \\
\hline Respiratory syncytial virus & $\begin{array}{c}\text { Blumea laciniata (Asteraceae) } \\
\text { Scutellaria indica (Labiatae) }\end{array}$ \\
\hline Enteroviruses & $\begin{array}{l}\text { Ocimum basilicum (Lamiaceae) } \\
\text { Salvia miltiorrhiza (Lamiaceae) }\end{array}$ \\
\hline Human immunodeficiency virus (HIV) & Zingiber officinale (Zingiberaceae) \\
\hline
\end{tabular}




\begin{tabular}{|c|c|}
\hline & $\begin{array}{c}\text { Solanum Niger (Solanaceae) } \\
\text { Piper methysticum (Piperaceae) }\end{array}$ \\
\hline Denovirus & Ocimum basilicum (Lamiaceae) \\
\hline
\end{tabular}

Table 1: list of plants showing anti-viral properties against various viruses [23]

\section{Advantages of Herbal Medicines [23]}

- The wide prescription of herbal drugs is mainly due to their effectiveness, less side effects and relatively low in cost.

- Therapeutic uses of herbal medicinal plants in numerous ailments also have a further important advantage of their easy availability.

- $\quad$ Easy to manufacture and even with the small quantity they are more effective when compared to the synthetic medications.

- Most herbal medicines are well tolerated by the patient, with little unintended consequences than the pharmaceutical drugs.

\section{Disadvantages of Herbal Medicines}

- By using herbal medicines, we cannot treat sudden illness or accidents, whereas modern medicines are very effective in this case.

- Another drawback of herbal medicine is that herbal treatments can interact with medications

- Manufacturing herbal medicines is a time-consuming process and it is complicated too

- Herbal drugs have slower effects as compare to Allopathic dosage forms, also it requires long term therapy \& even it is difficult to mask taste and odor

- Till date no pharmacopoeia defines any specific procedure or ingredients to be used in any herbal formulations.

\section{Recent Marketed Herbal Medicine for the Treatment of Covid-19}

Coronavirus disease 2019 (COVID-19) is a new communicable disease caused by severe acute respiratory syndrome coronavirus 2 (SARS-CoV2) that belongs to the coronavirus family [24]. By using antiviral drugs and immunomodulators, the research has showed that the drugs were not remarkably effective against the disease. Then, people believed that herbal immunomodulators or natural medicinal compounds might show effective results for the treatment of COVID-19 than the synthetic antivirals. During this pandemic situation many institutions and researchers are working for the herbal agents which can show better results. Some herbal agents extracted from various plants includes Echinacea, Cinchona, Curcuma longa, withania somnifera, Tinospora cardifolia and Curcuma xanthorrhiza, are considered to be good for the treatment of COVID-19 [25].

Among infected patients, COVID-19 manifests various unspecific symptoms, ranging from mild to severe which includescough $(76 \%)$, fever $(98 \%)$, sputum production $(28 \%)$ and headache $(8 \%)$. Presently, there is no specific treatment for COVID-19, people in the society and researchers are trying to find best way to cure the disease by using herbal medicines [26].

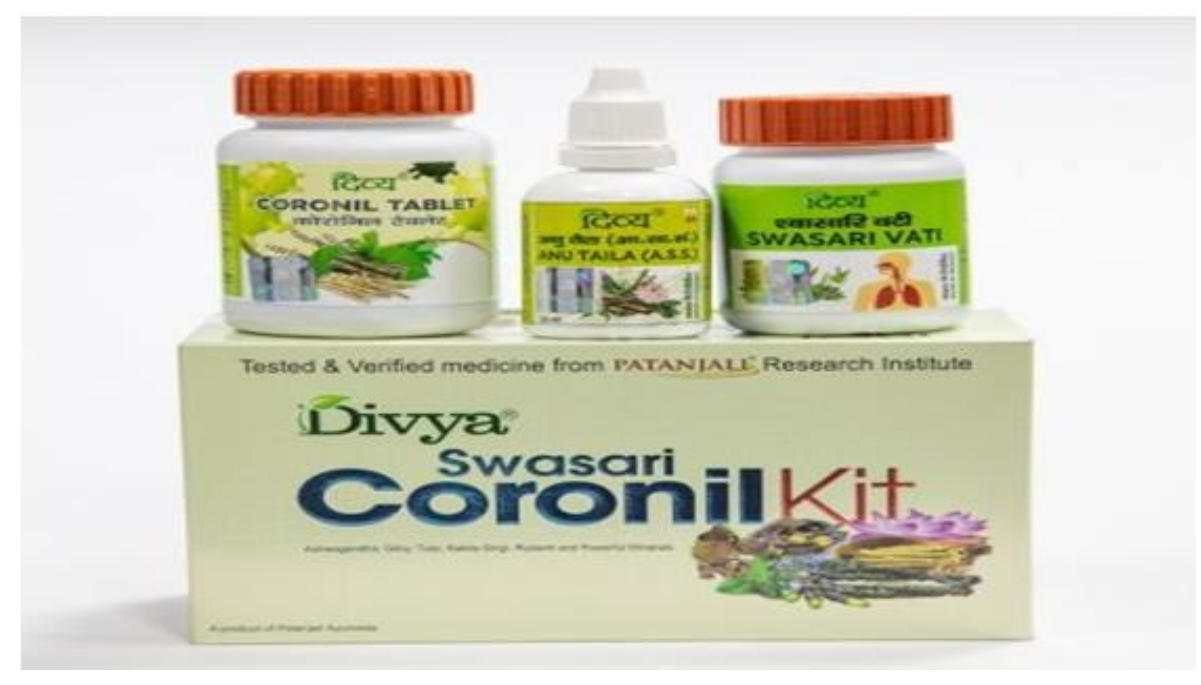

Figure 3: Herbal medicine for COVID-19 (Divya swasari coronil kit)

Many researchers and institutions are trying hard for the medicine and everyone are waiting for the medicine at this pandemic situation, the first ever clinically tested, evidence based ayurvedic medicine for curing deadly coronavirus has launched into the market by Patanjali Ayurveda Limited using traditional medicinal herbs. It has been named “CORONIL" [27, 28].

The Coronil kit consist of 3 products which are divyaCoronil tablets, divyaSwasarivati which are oral tablets used as immunity boosting agent and third product is Anu tali which is a liquid dosage form taken as nasal drops [29]. This medicine is purely herbal medicine which includes herbs like Giloy (Tinospora cardifolia), Ashwagandha (Withania somnifera) and Tulsi (Ocimum sanctum), etc. This herbal medicine good impact on patients who are affected with the coronavirus. This herbal medicine has huge benefits in strengthening the immune system and also are effective in curing symptoms like sore throat, nasal congestion, fever etc. not only giloy, ashwagandha and tulsi they have used 100 herbal compounds for the preparation of Coronil, therefore it showed good effect in patients suffering from coronavirus at this pandemic time. 

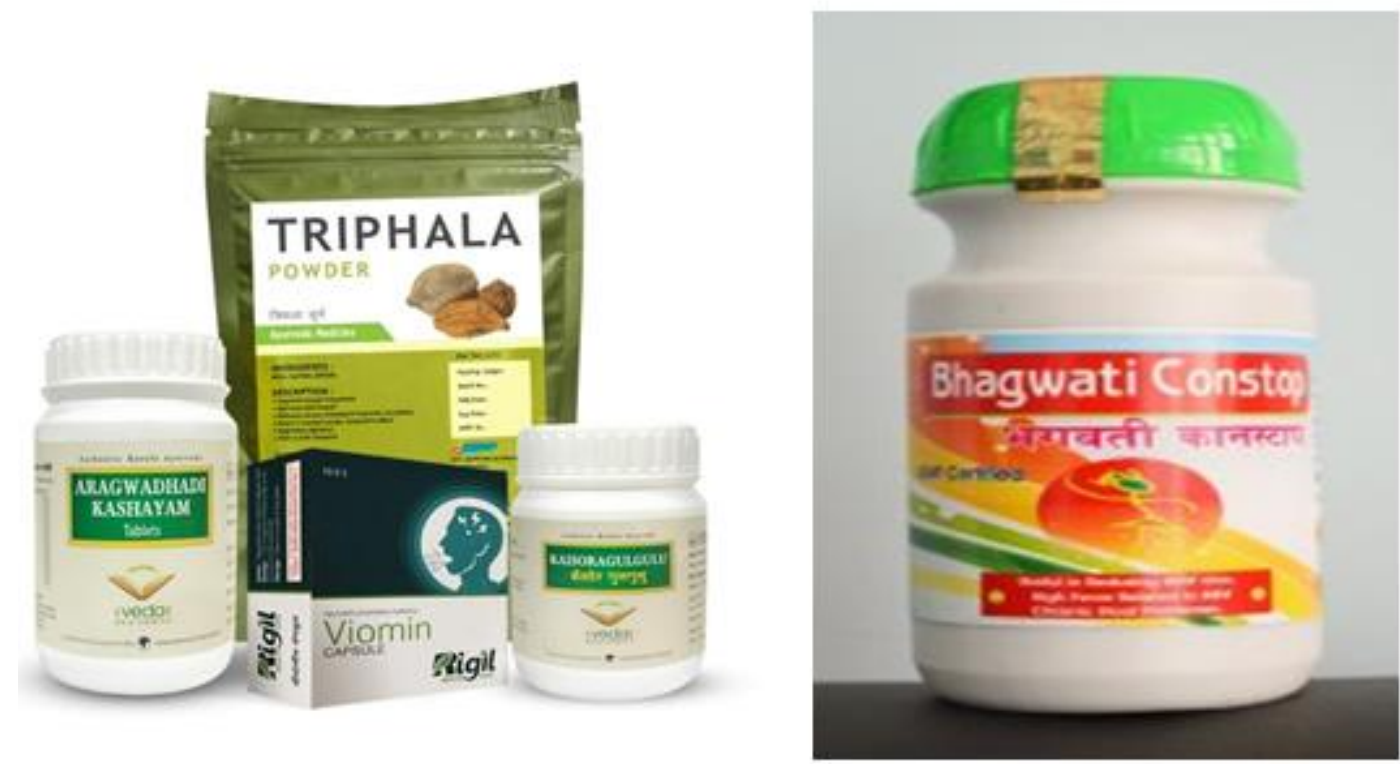

Figure 4: Marketed herbal medicine used for the treatment of HIV and herpes simplex viruses

\section{Discussion:}

Development of antiviral resistance is mainly correlated with viral fitness and the potency and genetic barrier to resistance of anti-viral agents. Potency of a drug is defined by time taken by drug to repress the viral replication. More hurriedly a drug suppresses the replication, lower the risk of developing anti-viral resistance. The anti-viral agents generally obstruct steps in virus-specific replication. These agents are capable of targeting viral enzymes, thus interfering with viral nucleic acid synthesis. There are many novel anti-viral agents developed currently to treat viral infections. The problem of antiviral resistance makes most of the antiviral drugs ineffective. Still a lot of work has to be done to further investigations in to its actual potential for human use.

There is an urgent need for the development of new formulations having effective antiviral properties. In present scenario there are severe side effects for the pharmaceutical drugs, advanced antiviral herbal formulations with less side effects, inherently safer for all, more effective and less expensive herbal formulations should be developed for treating viral infections. Herbal medicines and purified natural products come up with a rich resource for anti-viral drug development.

\section{Conclusion:}

Altogether, the declaration submitted in this work supports the notion that medicinal plants have promising therapeutic potential, especially in case of herbal products against viral infections. Promising results were observed for herbal antiviral agents by conducting a number of epidemiological and animal model studies for cellular and sub-cellular targets. Knowledge based on traditional system of medicines, various herbal formulations from medicinal plants for treating different viral infections has still to be developed. Many countries around the world are depending on their research for the formulation of herbal medicines against viral infections. There are several infectious diseases caused by viruses, many western medications and vaccines are available but these are not fully effective against these infections due to the mutating strains of the viruses such as influenza virus. Herbal treatments help in stopping the viral replication and shortens the duration of illness. At this pandemic situation of COVID-19, herbal agents are useful for the treatment of infections like CORONIL TABLETS and many other herbal formulations has to developed because the herbs having low cost, minimum toxicity almost found everywhere in the country, it has potential to enhance immunity to fight against the COVID-19 and for treating different diseases which are causing severe impact and now a days individual are more interested in herbal and ayurvedic medicines.

\section{References:}

1. S.A.A. Jassim, M.A. Naji. (2003). "Novel antiviral agents: a medicinal plant perspective", Journal of Applied Microbiology. 95(3):412-427.

2. Wang KC, Chang JS, Chiang LC, Lin CC. (2011). Sheng-Ma-Ge -Gen-Tang (Shoma-kakkon-to) inhibited cytopathic effect of human respiratory syncytial virus in cell lines of human respiratory tract. J Ethnopharmacol. 135:538-44.

3. Tregoning JS, Schwarze J. (2010). Respiratory viral infections in infants: causes, clinical symptoms, virology, and immunology. Clin Microbiol Rev. 23:74-98.

4. Bishop RF, Davidson GP, Holmes IH, Ruck BJ. (1973). Letter: Evidence for viral gastroenteritis. N Engl J Med. 289(20):10961097.

5. Biesbroeck L, Sidbury R. (2013). Viral exanthems: an update. Dermatol Ther. 26:433-438.

6. Rago F, Paolino S, Rebora A. (2012). The challenge of diagnosing atypical exanthems: a clinico-laboratory study. J Am Acad Dermatol. 67:1282-1288.

7. Korba BE, Cote PJ, Wells FV, Baldwin B, Popper H, Purcell RH, et al. (1989). Natural history of woodchuck hepatitis virus infections during the course of experimental viral infection: molecular virologic features of the liver and lymphoid tissues. $J$ Virol. 63:1360-1370.

8. Omeed Memar BS, Stephen K Tyring MD. (2004). Cutaneous viral infections- journal of the American Academy of Dermatology. 33(2):279-287.

9. Ftika L, Maltezou H.C. (2013). Viral haemorrhagic fevers in healthcare settings. Journal of Hospital Infection. 83(3):185-192.

10. Romero JR, Newland JG. (2003). Viral meningitis and encephalitis: traditional and emerging viral agents. Semin Pediatr Infect Dis. 14:72-82. 
11. Cos P, Hermans N, De Bruyne T, Apers S, Sindambiwe JB, Vanden Berghe D, et al. (2002). Further evaluation of Rwandan medicinal plant extracts for their antimicrobial and antiviral activities. J Ethnopharmacol. 79:155-63.

12. Sulochana Kaushik, Ginni Jangra, Vaibhav Kundu, Jaya Prakash Yadav, Samander Kaushik. (2020). Anti-viral activity of zingiber officinale (ginger) ingredients against the chikungunya virus. 31(3): 270-276.

13. Jung San Chang, Kuo Chih Wang, Chia Feng Yeh, Den En Shieh, Lien Chai Chiang. (2013). Fresh ginger has anti-viral activity against human respiratory syncytial virus in human respiratory tract cell lines. 145(1):146-151.

14. Ahmad Ghorbani and Mahdi Esmaeilizadeh. (2017). Pharmacological properies of Salvia officinalis (sage)-journal of traditional and complementary medicine. 7(4):433-440.

15. Lien-chai chiang, Lean-Teik $\mathrm{Ng}$, pei-Win cheng and win chiang. (2005). Antiviral activities of extracts and selected pure constituents of ocimum basilicum, clinical and experimental pharmacology and physiology. 32(10):811-816.

16. Marciele Ribas Pilau, Sydney Hartz Alves, Luciane Teresinha Lovato. (2011). Antiviral activity of the Lippia graveolens (Mexican oregano) essential oil and its main compound carvacrol against human and animal viruses- Brazilian journal of microbiology. 42(4):1616-1624.

17. Razina Rouf, Shaikh Jamal Uddin and Satyajit D. Sarker. (2020). Antiviral potential of garlic (Allium sativum) and its organosulfur compounds; a systemic update of pre-clinical and clinical dataTrends in food science and technology. 104: 219-234.

18. Ganguly B, Kumar N, Ahmad A H, Rastogi S. K. (2018). Influence ofphytochemical composition on in vitro antioxidant and reducingactivities of Indian ginseng [Withania somnifera (L.) Dunal] rootextracts. Journal of Ginseng Research. 42(4):463-469.

19. Vyas V. K, Bhandari P, Patidar R. (2011). A comprehensive review on Withania somnifera dunal. Journal of Natural Remedies: 11(1):1-13.
20. Balkrishna A, Pokhrel S, Singh J, \&amp; Varshney A. (2020). Withanone fromWithania somnifera may inhibit novel coronavirus (COVID-19) entry by disruptinginteractions between viral S-protein receptor binding domain and host ACE2receptor Virology Journal.

21. Ghosal S, Vishwakarma R A. (1997). Tinocordiside, a new rearrangedcadinane sesquiterpene glycoside from Tinospora cordifolia.Journal ofNatural Products. 60(8):839-841.

22. Sharma U, Bala M, Kumar N, Singh B, Munshi R K, Bhalerao S. (2012). Immunomodulatory active compounds from Tinospora cordifo-lia.Journal of Ethnopharmacology,141(3), 918-926.

23. Ruwali pushpa, Rai Nishant, Kumar Navin, Gautam Pankaj (2013). Antiviral potential of medicinal plants: An overview, international research journal of pharmacy. 18(13):2230-8407.

24. Li SY, Chen C, Zhang HQ, Guo HY, Wang H, Wang L, et al. (2005). Identification of natural compounds with antiviral activities against SARS-associated coronavirus. Antivir Res. $67: 18-23$

25. World Health Organization (WHO). (2020). Coronavirus disease (COVID-19) situation report-141 situation in numbers (by WHO Region). In Data asreceived by WHO from national authorities by 10:00 CEST, 13 May 2020.

26. Dharmendra M, Deepak S. (2020). Evaluation of traditional ayurvedic preparation for prevention and management of the novel coronavirus (SARS-CoV-2) using molecular docking approach.

27. Allen Loyd. (2008). Dosage Form Design and Development. Clinical therapeutics. 30. 2102-11.

28. Lai C C, Shih T P, Ko W C, Tang H J, Hsueh P R. (2020). Severe acute respiratory syndrome coronavirus 2 (SARS-CoV-2) and coronavirus disease-2019 (COVID-19): The epidemic and the challenges. International Journal of Antimicrobial Agents: 55:105924.

29. Kumari J. (2020). Patanjali Launches Coronavirus Medicine: What is Coronil and How it Helps in Treating COVID-19 Patients?
This work is licensed under Creative Commons Attribution 4.0 License

To Submit Your Article Click Here: Submit Manuscript

DOI: $10.31579 / 2692-9406 / 088$
Ready to submit your research? Choose Auctores and benefit from:

$>$ fast, convenient online submission

$>$ rigorous peer review by experienced research in your field

$>$ rapid publication on acceptance

$>$ authors retain copyrights

$>$ unique DOI for all articles

$>$ immediate, unrestricted online access

At Auctores, research is always in progress.

Learn more https://www.auctoresonline.org/journals/biomedical-research-andclinical-reviews- 